\title{
O PROGRAMA DE AQUISIÇÃO DE ALIMENTOS E SUA DISTRIBUIÇÃO ENTRE OS MUNICÍPIOS BRASILEIROS
}

\author{
The Program of Food Acquisition and its Distribution among Brazilian Municipalities
}

\begin{abstract}
RESUMO
No presente trabalho, analisou-se a distribuição espacial do Programa de Aquisição de Alimentos (PAA), ao longo dos municípios brasileiros. De forma específica, investigou-se a reformulação que se teve no programa, a partir de 2012, acarretou numa ampliação de municípios atendidos, e se privilegiaram os pontos nos quais se concentram a maior parte dos agricultores familiares no país. Para isso, foram separadas as modalidades do PAA operadas pela CONAB versus as modalidades operadas pelos estados e municípios. Na sequência, realizou-se uma análise exploratória de dados espaciais. Os resultados demonstraram uma ampliação dos municípios participantes do programa, embora o montante tenha diminuído nos últimos anos. Essa distribuição dos municípios participantes beneficiou todas as regiões brasileiras, concentrando-se, especialmente, nos pontos em que a agricultura familiar é mais presente. De forma preliminar, pode-se inferir que a reformulação do PAA está atingindo o objetivo de ampliar o número de municípios envolvidos no programa.
\end{abstract}

Augusta Pelinski Raiher

Universidade Federal do Rio Grande do Sul

apelinski@gmail.com

Ana Paula Moreira

Universidade de Brasília

aluapm@gmail.com

Recebido em: 04/09/2016. Aprovado em: 16/01/2019.

Avaliado pelo sistema double blind review.

Avaliador cientifíco: Renato Silvério Campos

Doi: 10.21714/2238-68902018v20n2p075

\begin{abstract}
The purpose of this study is to analyze the spatial distribution of the Food Acquisition Program (PAA) along Brazil's municipalities. More specifically, it seeks to analyze the redesign that was in the program from 2012 resulted in an expansion of municipalities, and favored the points that concentrate most of the farmers in the country. To this end, the modalities of PAA operated by Conab and the states and municipalities were separated. An exploratory spatial data analysis was carried out. The results showed an expansion of program participant municipalities, although the amount has decreased in recent years. This distribution of the participating municipalities benefited all regions of Brazil, focusing especially at the points where family farming is more present. Preliminarily, it can be inferred that the reformulation of the PAA is reaching the goal of increasing the number of municipalities involved in the program.
\end{abstract}

Palavras-chave: PAA, Agricultura Familiar, CONAB.

Keywords: PAA, Family Farming, CONAB.

\section{INTRODUÇÃO}

A agricultura familiar apresenta-se como decisiva na dinâmica da agropecuária brasileira, respondendo por $84,4 \%$ dos estabelecimentos agrícolas, contribuindo com $40,5 \%$ da produção nacional (IBGE, 2016). No entanto, na contramão dessa importância, ocupa um percentual de terras bastante ínfimo, trabalhando com apenas $24 \%$ da área total. Ou seja, os agricultores familiares precisam retirar de uma menor área, renda suficiente para a sua permanência no meio rural e de seus familiares.

Por isso, todo apoio dado a esse modelo produtivo se torna importante, seja por meio de políticas agrárias e agrícolas específicas seja também, por meio da valorização da produção procedente desses agricultores. E uma das políticas recentemente dirigidas a esse segmento refere-se ao Programa de Aquisição de Alimentos (PAA), formulado em 2003.

Basicamente, dois objetivos permeiam o programa. $\mathrm{O}$ primeiro refere-se à promoção do acesso à alimentação e o segundo está no incentivo dado à agricultura familiar. A dinâmica ocorre quando se adquirem alimentos da agricultura familiar, com dispensa de licitação, repassandoos aos programas públicos e organizações sociais, com o intuito de oportunizar o acesso aos alimentos, especialmente daqueles indivíduos que estão em risco 
alimentar. Nesse sentido, o PPA tenta fortalecer dois elos frágeis da dinâmica social do país, integrando-os, garantindo alimentos em quantidade e qualidade às pessoas em situação de insegurança alimentar e nutricional, ao mesmo tempo em que promove o fortalecimento da agricultura familiar.

Focando especialmente nos seus efeitos sobre a agricultura familiar, o formato e as condicionalidades do PAA induzem para que se promova a organização da agricultura familiar, fortalecendo os circuitos locais e regionais, as redes de comercialização, a diversificação da propriedade, a valorização da biodiversidade, juntamente com a produção de alimentos orgânicos e agroecológicos.

Empiricamente, diferentes autores conseguiram mensurar esses efeitos do PAA sobre a agricultura familiar. Por exemplo, Matos e Noia (2014) e Becker et al (2010) identificaram a importância do programa para a sustentabilidade da agricultura familiar, já outros autores, como Pereira e Lourenzani (2014), observaram um efeito positivo do programa na renda dos produtores. Ou seja, evidências empíricas demonstram um feito positivo do PAA para toda a dinâmica da agricultura familiar brasileira.

No final de 2012, o PAA passou por um conjunto de mudanças institucionais e normativas, visando a diminuir a centralidade que o programa apresentava. Originalmente, as diferentes modalidades do PAA eram operadas principalmente em parceria com a Companhia Nacional de Abastecimento (Conab). Na sua reformulação, esse papel crucial da Conab foi reduzido.

Na composição anterior, a obrigação de celebrar e gerir convênios com cada unidade executora do PAA era do MDS, executado pela Conab, fator que estabelecia um teto à expansão do Programa por conta dos limites e da estrutura operacional e administrativa do órgão. Dessa forma, ao estabelecer convênios -com a transferência de recursos financeiros- tal órgão tinha toda a responsabilidade de acompanhar a execução físicofinanceira, as contrapartidas previstas, de acompanhar e fiscalizar os cronogramas de desembolsos, validando todas as prestações de contas.

Com as alterações efetuadas a partir de 2012, parte dessas funções foram descentralizadas. No novo modelo, o MDS faz a transferência de recursos diretamente para o agricultor, e os estados/municípios que participam do programa ficam responsáveis pelo registro no sistema informatizado (SIS-PAA) de todos os dados necessárias para que o MDS autorize esse pagamento. Ademais, os estados/municípios também ficam responsáveis pela emissão de toda a documentação fiscal referente à operacionalização do programa, acompanhando e fiscalizando a aquisição dos produtos, sua qualidade, além de armazenar e de entregar tais produtos. Ou seja, criouse a possibilidade de execução do programa por estados, municípios e consórcios públicos sem a necessidade de celebração de convênio, a partir da adesão ao programa, com a possibilidade de que os pagamentos aos agricultores familiares fornecedores sejam feitos diretamente pela União.

Enfim, com a efetivação dessas e outras mudanças, a expectativa que se tem é de expansão do programa, com maior controle público dos recursos empregados. Essa expansão é esperada, principalmente, por meio do alargamento do programa para os municípios mais afastados das capitais, nos quais se concentram, de forma mais significativa, os agricultores familiares. E é diante desse objetivo que se insere este artigo, cuja meta é a de analisar a distribuição espacial do Programa de Aquisição de Alimentos (PAA), ao longo dos municípios brasileiros a partir de 2012. De forma específica, busca avaliar se a reformulação que se teve no programa a partir de 2012 acarretou numa ampliação de municípios atendidos, e se privilegiaram os pontos nos quais se concentram a maior parte dos agricultores familiares no país.

Para isso, tem-se cinco seções, incluindo esta. $\mathrm{Na}$ segunda, são apresentadas evidências empíricas acerca da importância do PAA para a agricultura familiar. $\mathrm{Na}$ sequência, tem-se os elementos metodológicos. $\mathrm{Na}$ quarta seção, é feita a análise da distribuição espacial do programa, bem como se analisa a evolução que se teve em termos de municípios participantes do programa e do valor destinado ao programa a partir de 2012. Por fim, apresentam-se as considerações finais.

\section{PROGRAMA DE AQUISIÇÃO DE ALIMENTOS: CARACTERÍSTICAS E OBJETIVOS}

No ano de 2003, foi instituído o Programa Fome Zero (PFZ), representando um grande marco, por meio do qual se aglutina um conjunto de programas de caráter imediato e de natureza estrutural, implementados, por meio de instrumentos de políticas públicas.

O PFZ tinha como proposta atuar articuladamente em quatro eixos centrais: 1) acesso à alimentação; 2) geração de renda; 3) fortalecimento da agricultura familiar e 4) articulação, mobilização e controle social 
e é, nesse plano, que se inscrevem algumas ações, que foi concebido para articular, um conjunto amplo de políticas públicas.

De um lado, tem-se as políticas de transferência direta de renda (programa bolsa-família), distribuição de alimentos, merenda escolar, etc. De outra parte, constam ações voltadas à reordenação fundiária, apoio à instalação de jovens agricultores, acesso a políticas públicas de fomento à produção da agricultura familiar, entre outras. É exatamente nesse contexto que emerge o Programa de Aquisição de Alimentos (PAA), objeto deste estudo.

O PAA é instrumento de política pública, instituído em 2003 pelo artigo 19 da Lei $n^{\circ}$. 10.696, "com a finalidade de incentivar a agricultura familiar, compreendendo ações vinculadas à distribuição de alimentos de produtos agropecuários para pessoas em situação de insegurança alimentar e à formação de estoques estratégicos (art. 19 - caput da referida lei). Essa Lei foi alterada pela Lei $n^{\circ} 12.512$, de 14 de outubro de 2011. O PAA foi ainda regulamentado por diversos decretos, o que está em vigência é o Decreto ${ }^{\circ} 7.775$, de 4 de julho de 2012.

Trata-se do primeiro programa de compras públicas e tem como objetivo principal incentivar a agricultura familiar via à aquisição de produtos agropecuários, por meio da produção de alimentos e sua distribuição em quantidade, qualidade e regularidade necessárias às populações em situação de insegurança alimentar e nutricional (HESPANHOL, 2009).

O Programa é "operacionalizado" pela Companhia Nacional de Abastecimento (CONAB), em parceria com Estados e municípios, com verbas destinadas pelo Ministério do Desenvolvimento Social e Combate à Fome (MDS) e Ministério de Desenvolvimento Agrário (MDA).

Em discussão ao modelo operacionalizado do PAA à agricultura familiar, surgem questões importantes a serem consideradas. Conforme Vinha e Schiavenatto (2015), o PAA sinaliza para uma mudança importante na política nacional de desenvolvimento rural brasileira: concede espaço político a sujeitos que não estão ligados aos interesses comandados pelo latifúndio e agronegócio e atribui um papel importante que institucionaliza as demandas da agricultura camponesa e da soberania alimentar.

Essa política tenta dar voz a outras relações sociais, sujeitos e territórios, rompendo com o centralismo e sinalizando que existe um outro modelo de desenvolvimento para o campo, baseado na agricultura familiar.
Trata-se do primeiro programa de compras públicas com uma orientação exclusiva para a agricultura familiar, destinado à aquisição de produtos agropecuários produzidos por agricultores enquadrados no Programa Nacional de Fortalecimento da Agricultura Familiar (PRONAF), estabelecidos para os grupos A, B, C e D e, preferencialmente, estarem organizados em cooperativas, associações ou grupos de interesse informais com, no mínimo, cinco agricultores. Incluídas aqui também as categorias assentados da reforma agrária, trabalhadores rurais sem terra, acampados, quilombolas, agroextrativistas, famílias atingidas por barragens e comunidades indígenas.

O programa incentiva a diversificação produtiva, por meio de suas modalidades e proporciona condições de mercado seguras, a preços justos (os produtos são adquiridos por órgãos do Governo Federal, por meio de preços de mercado sem a necessidade de licitação), necessários para a comercialização dos produtos, que podem contribuir efetivamente na melhoria das condições de produção e renda na agricultura familiar.

Recentemente, em 2012, foi instituída mais uma modalidade ao PAA, que amplia as possibilidades de mercados. Trata-se da Compra Institucional que permite aos estados, municípios e órgãos federais da administração direta e indireta adquirir alimentos da agricultura familiar, por meio de chamadas públicas, com seus próprios recursos financeiros, com dispensa de licitação.

Essa iniciativa fomenta governos estaduais a criarem suas próprias estratégias de compras públicas e estimula as organizações da agricultura familiar a constituírem novos mercados.

Conforme Peixoto e Oliveira (2015, p. 79)

dentre as finalidades do PAA está o incentivo à agricultura familiar, promovendo a sua inclusão econômica e social, com fomento à produção com sustentabilidade, ao processamento de alimentos e industrialização e à geração de renda, além de proporcionar o acesso à alimentação, em quantidade, qualidade e regularidade necessárias para pessoas em situação de insegurança alimentar e nutricional, com o fortalecimento de circuitos locais e regionais e redes de comercialização.

Como descrito acima, O PAA surge no circuito de políticas públicas para estímulo a agricultura familiar, na criação de canal de comercialização, promoção do desenvolvimento local, na descentralização políticoadministrativa para sua operacionalização, com preços justos e garantindo renda aos agricultores familiares. 
QUADRO 1 - Modalidades do PAA

\begin{tabular}{|c|c|c|c|c|}
\hline Modalidade & Forma de acesso & Limite & $\begin{array}{c}\text { Origem do } \\
\text { Recurso }\end{array}$ & Ação \\
\hline \multirow[b]{2}{*}{$\begin{array}{l}\text { Compra da Agricultura } \\
\text { Familiar para Doação } \\
\text { Simultânea }\end{array}$} & Individual & $\mathrm{R} \$ 4,5 \mathrm{mil}$ & \multirow[b]{2}{*}{ MDS } & \multirow[b]{2}{*}{$\begin{array}{l}\text { Responsável pela doação de produtos adquiridos da } \\
\text { agricultura familiar a pessoas em situação de insegurança } \\
\text { alimentar e nutricional. }\end{array}$} \\
\hline & $\begin{array}{l}\text { Organizações } \\
\text { (cooperativas/ } \\
\text { associações) }\end{array}$ & $\mathrm{R} \$ 4,8$ mil & & \\
\hline $\begin{array}{l}\text { Formação de Estoques } \\
\text { pela Agricultura } \\
\text { Familiar - CPR Estoque }\end{array}$ & $\begin{array}{l}\text { Organizações } \\
\text { (cooperativas/ } \\
\text { associações) }\end{array}$ & $\mathrm{R} \$ 8$ mil & $\begin{array}{l}\text { MDS/ } \\
\text { MDA }\end{array}$ & $\begin{array}{l}\text { Disponibiliza recursos para que organizações da } \\
\text { agricultura familiar formem estoques de produtos para } \\
\text { posterior comercialização. }\end{array}$ \\
\hline $\begin{array}{l}\text { Compra Direta da } \\
\text { Agricultura Familiar } \\
\quad-\text { CDAF }\end{array}$ & $\begin{array}{l}\text { Individual ou } \\
\text { organizações } \\
\text { (cooperativas/ } \\
\text { associações) }\end{array}$ & $\mathrm{R} \$ 8$ mil & $\begin{array}{l}\text { MDS/ } \\
\text { MDA }\end{array}$ & $\begin{array}{l}\text { Voltada à aquisição de produtos em situação de baixa } \\
\text { de preço ou em função da necessidade de atender a } \\
\text { demandas de alimentos de populações em condição de } \\
\text { insegurança alimentar. }\end{array}$ \\
\hline $\begin{array}{l}\text { Incentivo à Produção } \\
\text { e Incentivo de Leite - } \\
\text { PAA Leite }\end{array}$ & $\begin{array}{l}\text { Individual ou } \\
\text { organizações } \\
\text { (cooperativas/ } \\
\text { associações) }\end{array}$ & $\begin{array}{l}\mathrm{R} \$ 4 \\
\text { mil por } \\
\text { semestre }\end{array}$ & MDS & $\begin{array}{l}\text { Assegura a distribuição gratuita de leite em ações de combate } \\
\text { à fome e à desnutrição de cidadãos que estejam em situação } \\
\text { de vulnerabilidade social e/ou em estado de insegurança } \\
\text { alimentar e nutricional. Atende os estados do Nordeste. }\end{array}$ \\
\hline Compra Institucional & $\begin{array}{l}\text { Individual ou } \\
\text { organizações } \\
\text { (cooperativas/ } \\
\text { associações) }\end{array}$ & $\mathrm{R} \$ 8$ mil & $\begin{array}{c}\text { Órgão } \\
\text { Proponente }\end{array}$ & $\begin{array}{l}\text { Compra voltada para o atendimento de demandas } \\
\text { regulares de consumo de alimentos por parte da União, } \\
\text { Estados, Distrito Federal e Municípios; }\end{array}$ \\
\hline
\end{tabular}

Fonte: Secretaria Especial de Agricultura Familiar e Desenvolvimento Agrário (2016)

\subsection{Evidências Empíricas do Efeito do PAA sobre o Fortalecimento da Agricultura Familiar}

No ano de 2016, o PAA completou treze anos de operacionalização, sendo margem de inúmeras avaliações de impactos e resultados. Dentre as análises efetuadas, boa parte avalia o estímulo para a permanência do agricultor no campo, o aumento da renda familiar, a criação do canal de comercialização e, ainda, observam os impactos do PAA na segurança alimentar e nutricional da população beneficiária, seu financiamento, abrangência territorial, articulação intersetorial, dentre outros pontos.

Cabe sinalizar o campo de inovações que o PAA traz para a política pública, que o fez repercutir no cenário internacional, conforme Grisa e Porto (2015, p.156),

Para alem do cenário nacional, o Programa passou a despertar a atenção também de agências multilaterais internacionais e de outros países. A criação do PAA África (Purchase from Africans for Africa) em 2010, envolvendo cinco países da África Subsariana, e iniciativas de construção de programa similares na América Latina são emblemáticas da importância internacional adquirida pelo Programa.

No Quadro 2, são apresentadas algumas evidências empíricas sobre o programa, as quais sinalizam sua contribuição para o desenvolvimento rural brasileiro.
Nessa premissa, é inegável os avanços que o PAA trouxe ao contexto da política agrária no Brasil. E essa importância revelada por diferentes autores reforça a necessidade de se ampliar cada vez mais o programa, o qual beneficia dois públicos alvos que, historicamente, ficaram à mercê das políticas públicas: os agricultores familiares e os beneficiários (pessoas em situação de insegurança alimentar e vulnerabilidade socioeconômica).

\section{METODOLOGIA}

O PAA foi instituído em 2003, ganhando maior visibilidade a partir de 2010, com a implantação do programa "Fome Zero". No entanto, no final de 2012 ele foi redesenhado, com a descentralização tanto da sua política como da sua execução. O objetivo dessa reformulação era ampliar os municípios atendidos pelo programa. Por isso, o período analisado, neste estudo, inicia-se em 2012, indo até 2015, fase da mudança do PAA. Não se avalia o período anterior dado que já se tem uma literatura bastante extensa que faz tal investigação; entretanto, análises pós 2012, especialmente visando à descentralização do programa, são poucas, além do que não são desagregadas como se fez neste artigo. 
QUADRO 2 - Resumo das evidências empíricas - efeito do PAA no fortalecimento da agricultura familiar (AF)

\begin{tabular}{|c|c|c|c|}
\hline Autor (res) & $\begin{array}{l}\text { Variável (eis) - } \\
\text { fortalecimento da } \mathrm{AF}\end{array}$ & $\begin{array}{l}\text { Metodologia } \\
\text { usada }\end{array}$ & Resultado \\
\hline $\begin{array}{l}\text { Bezerra e } \\
\text { Schneider } \\
(2012, \text { p.39) }\end{array}$ & $\begin{array}{l}\text { Crise do modelo } \\
\text { produtivista (modelo de } \\
\text { produção e consumo de } \\
\text { alimentos de ampla } \\
\text { comercialização e } \\
\text { produzidos em larga } \\
\text { escala) }\end{array}$ & $\begin{array}{l}\text { Análise tese } \\
\text { doutoral }\end{array}$ & $\begin{array}{c}\text { Abriu espaço para a discussão de proposições de } \\
\text { desenvolvimento local e sustentabilidade que envolve o } \\
\text { estabelecimento de formas de organização que facilitem a } \\
\text { intensificação e colaboração entre consumo e produção e, desse } \\
\text { modo, o Estado assume a função (re)definir por meio de suas } \\
\text { politicas e de seus programas de aquisições de alimentos modelos } \\
\text { diferenciados de abastecimento alimentar. }\end{array}$ \\
\hline $\begin{array}{l}\text { Becker, Anjos, } \\
\text { Bezerra }(2010, \\
\quad \text { p.16) }\end{array}$ & $\begin{array}{l}\text { Manutenção das } \\
\text { famílias na zona rural }\end{array}$ & $\begin{array}{l}\text { Estudo de } \\
\text { caso com } 60 \\
\text { agricultores } \\
\text { familiares de } 03 \\
\text { assentamentos } \\
\text { do estado do Rio } \\
\text { Grande do Sul }\end{array}$ & $\begin{array}{l}\text { O programa trouxe novas perspectivas para as suas atividades e } \\
\text { permanência da família no meio rural, na sua tentativa de conjugar } \\
\text { três importantes etapas, quais sejam, a produção, a comercialização } \\
\text { e o consumo, contemplando especificamente diversos grupos sociais } \\
\text { que, em boa medida, encontravam-se à margem dos processos } \\
\text { produtivos ou que por determinadas circunstâncias, estavam } \\
\text { submetidos a uma condição de reduzidas perspectivas no que } \\
\text { concerne à sua reprodução social enquanto agricultores familiares. }\end{array}$ \\
\hline $\begin{array}{l}\text { Matos e Noia } \\
(2014, \text { p. } 17)\end{array}$ & $\begin{array}{l}\text { Manutenção das } \\
\text { famílias na zona rural }\end{array}$ & $\begin{array}{l}\text { Método descritivo } \\
\text { junto aos atores } \\
\text { envolvidos no } \\
\text { programa no } \\
\text { município de } \\
\text { Itabuna - BA } \\
\end{array}$ & $\begin{array}{c}\text { O Programa permitiu a fixação dos agricultores no campo através } \\
\text { do incremento de sua renda, melhorando a qualidade de vida e o } \\
\text { incentivo para diversificar a produção. }\end{array}$ \\
\hline $\begin{array}{l}\text { Hespanhol } \\
(2009, \text { p. } 14)\end{array}$ & $\begin{array}{l}\text { Diversificação } \\
\text { produtiva }\end{array}$ & $\begin{array}{c}\text { Pesquisa empírica } \\
\text { com entrevistas } \\
\text { a presidentes } \\
\text { de associações } \\
\text { e agricultores } \\
\text { familiares de } \\
\text { Dracena, Tupi } \\
\text { Paulista e } \\
\text { Junqueirópolis }\end{array}$ & $\begin{array}{l}\text { Os agricultores pesquisados demonstraram interesse em ampliar } \\
\text { a área cultivada com gêneros alimentícios e/ou diversificar ainda } \\
\text { mais os cultivos realizados em pequenas áreas. }\end{array}$ \\
\hline $\begin{array}{l}\text { Hespanhol } \\
(2009, \text { p. } 15)\end{array}$ & $\begin{array}{l}\text { Aumento da renda } \\
\text { familiar }\end{array}$ & Idem & $\begin{array}{l}\text { O PAA tem se mostrado uma alternativa aos produtores } \\
\text { familiares, sobretudo para aqueles mais descapitalizados. }\end{array}$ \\
\hline $\begin{array}{c}\text { Pereira e } \\
\text { Lourenzani } \\
(2014, \text { p. } 236)\end{array}$ & $\begin{array}{l}\text { Aumento da renda } \\
\text { familiar }\end{array}$ & $\begin{array}{c}\text { Pesquisa } \\
\text { descritiva, com } \\
\text { questionário } \\
\text { semi-estuturado } \\
\text { a } 25 \text { agricultores } \\
\text { familiares de } \\
\text { Tupã - SP }\end{array}$ & $\begin{array}{c}84 \% \text { do total dos entrevistados, afirmaram percepção do } \\
\text { aumento após participação no PAA. Destes que responderam } \\
\text { afirmadamente, } 38 \% \text { acusaram um aumento de até } 20 \% \text { na renda, } \\
24 \% \text { acusaram um aumento entre } 21 \% \text { e } 40 \% \text { e } 5 \% \text { acusaram } \\
\text { aumento entre } 61 \% \text { e } 80 \% \text {. }\end{array}$ \\
\hline $\begin{array}{l}\text { Hespanhol } \\
(2009, \text { p. } 15)\end{array}$ & $\begin{array}{l}\text { Valorização hábitos } \\
\text { alimentares }\end{array}$ & $\begin{array}{c}\text { Pesquisa empírica } \\
\text { com entrevistas } \\
\text { a presidentes } \\
\text { de associações } \\
\text { e agricultores } \\
\text { familiares de } \\
\text { Dracena, Tupi } \\
\text { Paulista e } \\
\text { Junqueirópolis }\end{array}$ & $\begin{array}{l}\text { Ao considerar as particularidades locais/regionais, valoriza } \\
\text { os hábitos alimentares diferenciados da população brasileira, } \\
\text { estimulando a produção de gêneros alimentícios. }\end{array}$ \\
\hline
\end{tabular}

Continua... 
QUADRO 2 - Continuação...

\begin{tabular}{|c|c|c|c|}
\hline $\begin{array}{l}\text { Leal }(2015 \text {, } \\
\text { p.160) }\end{array}$ & $\begin{array}{l}\text { Limitações devido a } \\
\text { burocratização }\end{array}$ & $\begin{array}{l}\text { Estudo de } \\
\text { caso com } 03 \\
\text { assentamentos } \\
\text { do Pontal do } \\
\text { Paranapanema } \\
\quad-\text { SP }\end{array}$ & $\begin{array}{l}\text { Para acessar o Programa como supracitado os camponeses têm } \\
\text { que possuir a DAP e outros documentos. A posse da DAP está } \\
\text { sendo uma das principais limitações de acesso ao PAA. Se o } \\
\text { assentado não a possui, não consegue se cadastrar nas associações } \\
\text { e, consequentemente, não pode participar do Programa. Um } \\
\text { dos fatores que emperra a emissão da DAP é a renda, pois para } \\
\text { comprovarem os assentados têm que apresentar notas e/ou } \\
\text { comprovantes fiscais do que foi vendido no ano anterior. Isso é } \\
\text { um problema, pois os camponeses não têm costume de emitir } \\
\text { notas das suas operações de vendas. }\end{array}$ \\
\hline $\begin{array}{c}\text { Matos e Noia } \\
(2014, \text { p. } 17)\end{array}$ & $\begin{array}{l}\text { Redução da insegurança } \\
\text { alimentar e melhoria } \\
\text { da alimentação do } \\
\text { beneficiados }\end{array}$ & $\begin{array}{l}\text { Método descritivo } \\
\text { junto aos atores } \\
\text { envolvidos no } \\
\text { programa no } \\
\text { município de } \\
\text { Itabuna - BA }\end{array}$ & $\begin{array}{c}\text { A distribuição dos alimentos nas entidades contempladas } \\
\text { possibilita a redução da insegurança alimentar e nutricional } \\
\text { para as pessoas em condições de vulneráveis [...] o impacto na } \\
\text { melhoria da alimentação dos beneficiários, tanto em qualidade } \\
\text { quanto em variedade, foi satisfatório no que diz respeito a uma } \\
\text { alimentação mais saudável e com nutrientes necessários para } \\
\text { compor o cardápio diário. }\end{array}$ \\
\hline
\end{tabular}

Fonte: Organização da pesquisa

Os dados coletados foram obtidos diretamente na Conab e também no PAA DATA. Essas informações foram agregadas por municípios, tendo em vista que os dados originais estão disponibilizados em nível do agricultor. Informações acerca das modalidades operadas pela Conab estão disponíveis até 2015, mas as modalidades estaduais e municipais (disponíveis no PAA DATA) referiam-se somente até $2014^{1}$. Por isso, em alguns momentos, a análise abrangeu o ano de 2015 e, em outros, apenas até 2014.

Outra informação trabalhada foi o percentual de estabelecimentos da agricultura familiar, visando a correlacionar espacialmente com os recursos do PAA. Os dados acerca da agricultura foram obtidos no IBGE, com dados disponíveis apenas para o ano de 2006. Mesmo não correspondendo ao mesmo período, fez a análise supondo a existência do mesmo quadro de distribuição dos agricultores que se tinha a priori, com a hipótese de se ter rigidez na transformação do ambiente rural, especialmente por não se ter grandes acontecimentos nesse meio tempo que levassem a mudanças abruptas desse espaço.

Por fim, cabe-se ressaltar que a análise exploratória dos dados espaciais (AEDE) foi utilizada na investigação da distribuição espacial dos valores, bem como da participação dos municípios no programa. Infere-se que a correlação espacial entre a distribuição dos recursos do PAA e a concentração dos estabelecimentos da

${ }^{1}$ É importante destacar que a única modalidade do PAA não considerada nesta pesquisa referiu-se ao PAA Leite. agricultura familiar também foi feita por meio da mesma metodologia. A seguir, apresentam-se detalhes sobre a AEDE.

\subsection{Análise Exploratória dos Dados Espaciais (AEDE)}

Por meio desta metodologia, consegue-se descrever a distribuição espacial dos recursos do PAA- em termos de valores e de participação -, além de relacioná-los com a distribuição espacial da agricultura familiar. Com isso, é possível identificar os padrões de associação espacial que existem ao longo do país.

Para se implementar a AEDE, é necessária a adoção de uma matriz de ponderação espacial $(W)$. Almeida (2012, p. 76) destaca que essa é uma matriz quadrada de ordem $n$ por $n$, cujos elementos denotam o grau de conexão espacial entre os municípios em análise, seguindo algum critério de proximidade. No presente estudo, o critério de proximidade será baseado na contiguidade (com convenção do tipo torre, rainha e do vizinho mais próximo), em que se parte do pressuposto de que os municípios contíguos possuem uma interação mais forte do que os municípios que não são contíguos. Dessa forma, o elemento $w_{i j}$ da matriz de ponderação espacial $(W)$ terá valor igual a 1 quando dois municípios forem contíguos, e 0 em caso contrário.

Por convenção, o elemento $w_{i i}$ é igual a zero, pois um município não pode ser vizinho de si mesmo. $\mathrm{Na}$ implementação da AEDE serão utilizados os testes de autocorrelação espacial global univariada e bivariada. 


\subsubsection{Autocorrelação espacial global (univariada)}

Por meio da autocorrelação espacial global é possível identificar se a distribuição espacial de uma determinada variável se dá de forma aleatória ou não. Se a distribuição espacial for aleatória, o comportamento dessa variável na região $i$ não é influenciado pelo comportamento da mesma variável na região $j$. Destaca-se que a estatística I de Moran foi utilizada, nesta pesquisa, para fazer tal inferência, a qual é definida da seguinte forma:

$I=\frac{n}{S_{0}} \frac{z^{\prime} W z}{z^{\prime} z}$

Em que: $n$ denota o número de municípios brasileiros; $z$ é o valor dos recursos do PAA ou a participação do município no programa (padronizado); $W z$ representa os valores médios dos recursos ou da participação dos municípios no PAA (padronizados nos vizinhos), e definidos conforme a matriz de ponderação espacial adotada $(W) ; S_{0}$ é o somatório de todos os elementos da matriz de ponderação espacial $(W)$.

A hipótese nula a ser testada é a de que a distribuição espacial dos recursos ou da participação dos municípios no programa é aleatória. O valor esperado do teste é -[1/(n-1)]. Se existir aleatoriedade na distribuição espacial dos recursos entre os municípios brasileiros, a estatística $I$ de Moran deve ser igual ao seu valor esperado, conforme o nível de significância adotado; caso contrário, rejeita-se a hipótese nula. Um valor de $I$ maior do que o seu valor esperado indica uma autocorrelação espacial positiva nos recursos ou na participação dos municípios, e um valor abaixo do seu valor esperado corresponde a uma autocorrelação espacial negativa ${ }^{2}$.

\subsubsection{Autocorrelação espacial global (bivariada)}

A autocorrelação espacial global destacada na subseção anterior também pode ser empregada em um contexto bivariado (JUNIOR; ALMEIDA, 2009). Nesse caso, a proposta é descobrir se os valores de uma variável (y) observada em um determinado município têm uma relação sistemática com os valores de uma outra variável (x) observada nos municípios vizinhos. Em termos

${ }^{2}$ Uma autocorrelação espacial positiva significa que um município com valor ou participação do PAA elevada (baixa) está rodeada por municípios que também possuem um valor ou uma participação elevada (baixa) Quando a autocorrelação espacial é negativa, um município com elevado (baixo) valor ou participação no PAA está rodeada por municípios com valores ou participação baixa (elevada). formais, a estatística $I$ de Moran para duas variáveis diferentes, $y$ e $x$, fica:

$I^{y x}=\frac{n}{\Sigma_{i} \Sigma_{j} w_{i j}} \frac{\sum_{i} \Sigma_{j}\left(x_{i}-\bar{x}\right) w_{i j}\left(y_{i}-\bar{y}\right)}{\Sigma_{i}\left(x_{i}-\bar{x}\right)^{2}}$

Valores positivos e negativos do $I$ de Moran bivariado denotam concentração e dispersão espaciais, respectivamente. Destaca-se que, para a implementação desta estatística, $y$ será definido como os recursos do PAA ou a participação dos municípios no PAA, enquanto que $x$ será a participação dos estabelecimentos da agricultura familiar no total de estabelecimentos da agricultura.

\section{DISTRIBUIÇÃO ESPACIAL DO PAA}

$\mathrm{Na}$ sua formulação, o PAA centralizou seus objetivos em duas linhas: na segurança alimentar e no fortalecimento da agricultura familiar. Especialmente nesse segundo item, a sua ação basicamente busca promover a geração de renda, a diversificação da produção, o fortalecimento de organizações sociais, garantindo preço e mercado para a agricultura familiar. Ademais, todo o seu processo está apoiado em um ferramental que visa a diminuir a burocracia no processo de aquisição dos produtos da agricultura familiar.

Empiricamente, diversos trabalhos demonstram o efeito positivo do programa para o fortalecimento da agricultura familiar [conforme evidenciado anteriormente no Quadro 2. Portanto, a forma como o programa se distribui espacialmente se torna decisivo na dinâmica da sustentabilidade dessa categoria no meio rural. $\mathrm{Na}$ Figura 1 (a), são apresentados os municípios brasileiros que participaram do PAA nas modalidades operadas pela Conab (PAA-CONAB) ${ }^{3}$, entre os anos de 2012 e 2015 . Ao todo, 1.552 municípios participaram do PAA, comercializando em, pelo menos, um dos anos selecionados, apresentando uma distribuição que contempla todas as regiões brasileiras.

\footnotetext{
${ }^{3} \mathrm{Na}$ execução das modalidades geridas pela CONAB, a instituição firma Termo de Cooperação com o MDS e com o MDA. Entre os anos de 2003 e 2012, o PAA foi executado por estados, o Distrito Federal e municípios, por meio de convênios com o MDS. Depois de 2012, com a Lei $n^{\circ} 12.512 / 2011$, regulamentada pelo Decreto $n^{\circ} 7.775 / 2012$, abriu-se a possibilidade de execução do PAA mediante a celebração de Termo de Adesão, dispensada a celebração de convênio. Esse novo instrumento proporciona a ampliação do Programa, tem menos burocracia, além de possibilitar a realização do pagamento pela União, por intermédio do MDS, diretamente ao agricultor familiar, que o recebe por meio de um cartão bancário específico para o recebimento dos recursos do PAA.
} 
De forma mais precisa, na Tabela 1, tem-se o percentual de municípios incluídos no PAA-CONAB ao longo desses anos. Percebe-se que as regiões Norte, Nordeste e Centro-Oeste tiveram, respectivamente, os maiores percentuais de seus municípios inclusos no programa, embora a participação no valor total seja mais substancial para o Sudeste (28\%), Sul $(27 \%)$ e para o Nordeste $(27 \%)$. Isso demonstra uma concentração maior dos valores em alguns espaços, não detendo uma distribuição aleatória desses montantes.

Por mais que o valor do PAA-CONAB para o Nordeste tenha sido alto, respondendo por $27 \%$ dos recursos dessa modalidade em nível nacional, existe um número maior de municípios nessa região, bem como um percentual elevado de agricultores familiares, ressaltando que, quase metade (49\%) dos estabelecimentos familiares do Brasil, estavam localizados, nesta região, em 2006 (Tabela 1). Por isso, o resultado final é um valor médio do PAA-CONAB por estabelecimento da agricultura familiar menor para o Nordeste, bem como um menor valor médio por município participantes do programa (Tabela 1).

Ou seja, na perspectiva da concentração da agricultura familiar, esse resultado indica uma tendência de distorção quanto à distribuição dos valores do PAACONAB ao longo do Brasil.

Na Figura 1(b), tem-se a taxa de crescimento dos valores do PAA-CONAB entre 2012 e 2015. Observa-se que a grande maioria dos municípios ou permaneceram com os mesmos montantes ou diminuíram seus valores quando considerado 2015 versus 2012, com êxito apenas para 329 municípios que elevaram sua participação (6\% dos municípios brasileiros).

Esse cenário é decorrente da própria tendência que o PAA apresentou, com redução paulatina de seus montantes, a partir de 2013. Com feito, até o ano de 2012 o programa teve uma dinâmica positiva e significativa (HESPANHOL, 2013). Especialmente, no ano de 2010, com o lançamento do programa "Brasil sem Miséria", o PAA ganhou status estratégico na promoção da inclusão produtiva de pequenos produtores rurais em situação de extrema pobreza, refletindo num aumento significativo dos seus recursos, auferindo seu ápice no ano de 2012. Ressalta-se que o principal instrumento de realização desse objetivo se deu por meio da modalidade de doação simultânea, que é operada pela Conab.

Entretanto, no final de 2012, uma série de mudanças institucionais afetaram o formato do PAA, reduzindo o papel da Conab nesse processo, dando maior centralidade às modalidades estaduais e municipais (VALDARES E SOUZA, 2015). Tal fato justifica a queda ocorrida nos montantes do PAA-CONAB, as quais são verificadas na Tabela 2 .

Essas mudanças foram autorizadas pela Lei $\mathrm{n}^{\circ}$ 12.512/2011 e regulamentada pelo Decreto $n^{\circ} 7.775 / 2012$, cujo foco está na ampliação do programa, especialmente visando a atender ao público do plano "Brasil Sem Miséria", juntamente com os povos/comunidades tradicionais do país. Na composição anterior, a obrigação de celebrar e gerir convênios com cada unidade executora do PAA era do MDS, executado pela Conab, fator que estabelecia um teto à expansão do Programa por conta dos limites e da estrutura operacional e administrativa do órgão. Com efeito, ao estabelecer convênios -com a transferência de recursos financeiros- tal órgão tinha toda a responsabilidade de acompanhar a execução físicofinanceira, as contrapartidas previstas, de acompanhar e fiscalizar os cronogramas de desembolsos, validando todas as prestações de contas.

TABELA 1 - Estatísticas referentes ao valor do PAA- modalidades operadas pela CONAB - período 2012 a 2015regiões do Brasil **

\begin{tabular}{cccccccc}
\hline & $\begin{array}{c}\text { Munic. } \\
\text { partic. (\%) }\end{array}$ & $\begin{array}{c}\text { Valor médio por } \\
\text { mun. Partic. (R\$) }\end{array}$ & $\begin{array}{c}\text { Valor total } \\
\text { PAA (R\$) }\end{array}$ & $\begin{array}{c}\text { Partic. no valor } \\
\text { total (\%) }\end{array}$ & $\begin{array}{c}\text { Proporção por } \\
\text { município }\end{array}$ & $\begin{array}{c}\text { Estabel. Agric. } \\
\text { familiar (AF) }\end{array}$ & $\begin{array}{c}\text { PAA por } \\
\text { AF }\end{array}$ \\
\hline Sul & 22 & 1.327 .194 & 351706496 & 27 & 295800 & 879306 & 400 \\
Sudeste & 22 & 962.864 & 360111236 & 28 & 215894 & 729342 & 494 \\
Norte & 39 & 653.773 & 113756520 & 9 & 253355 & 438091 & 260 \\
Nordeste & 33 & 596.028 & 348676458 & 27 & 194465 & 2259184 & 154 \\
Centro-Oeste & 33 & 733.480 & 112955941 & 9 & 242395 & 244724 & 462 \\
\hline
\end{tabular}

Fonte: Resultado da pesquisa com dados originais da Conab e do IBGE

Nota: *Últimos dados disponíveis sobre a agricultura familiar referem-se a 2006, sendo utilizado esta informação. ** todos os dados monetários foram deflacionados $(2012=100)$ pelo IGP-DI

Organizações Rurais \& Agroindustriais, Lavras, v. 20, n. 2, p. 75-87, 2018 
(a) PAA - CONAB*

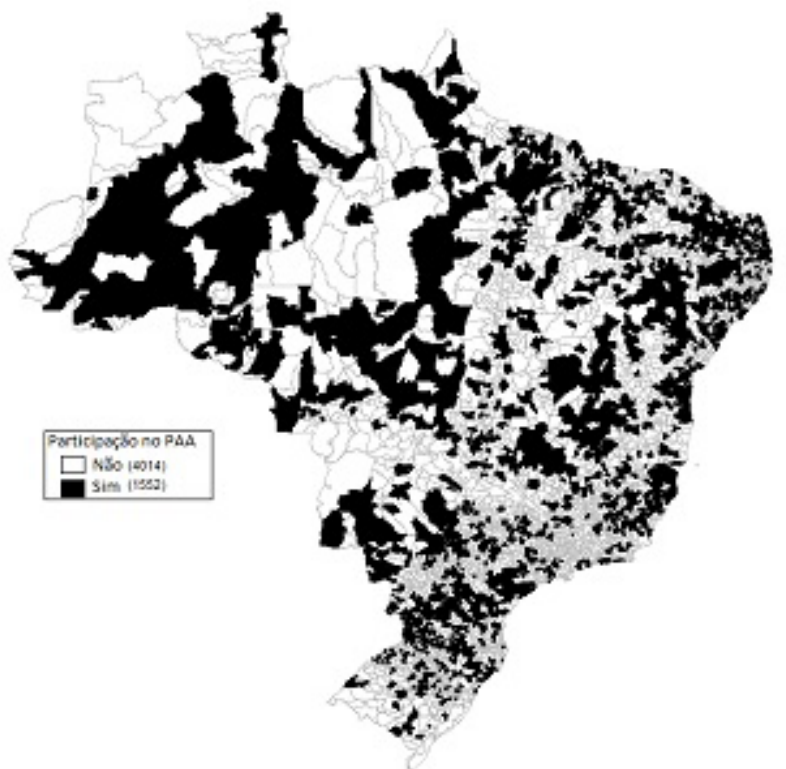

(c) PAA Estadual/Municipal**

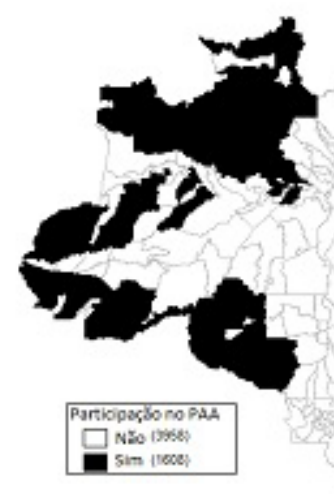

(b) Taxa de cresc. PAA-CONAB

(2012/2015)

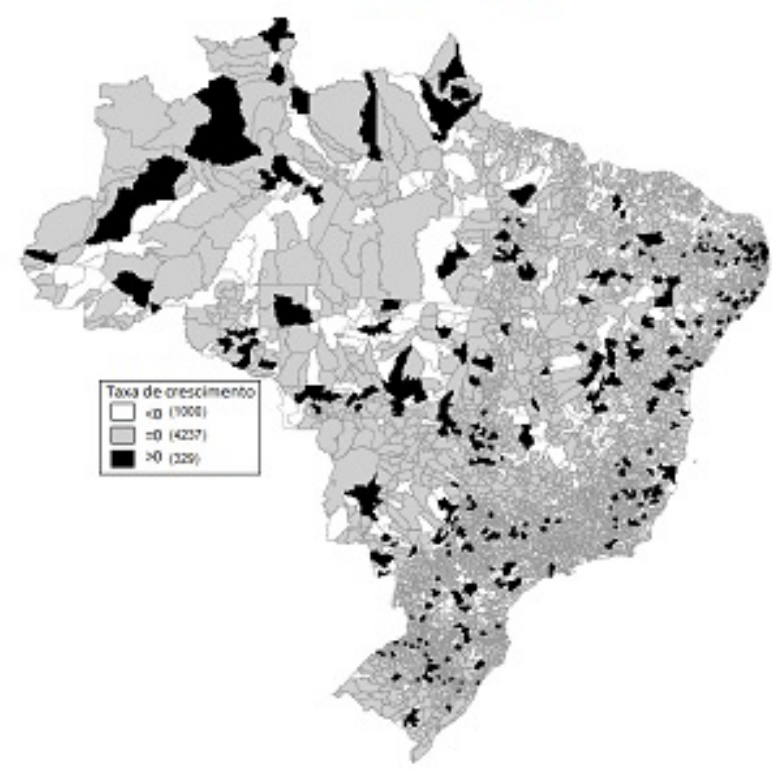

(d) PAA operações $\mathrm{CONAB}^{*}+$ Estadual/Municipa1**
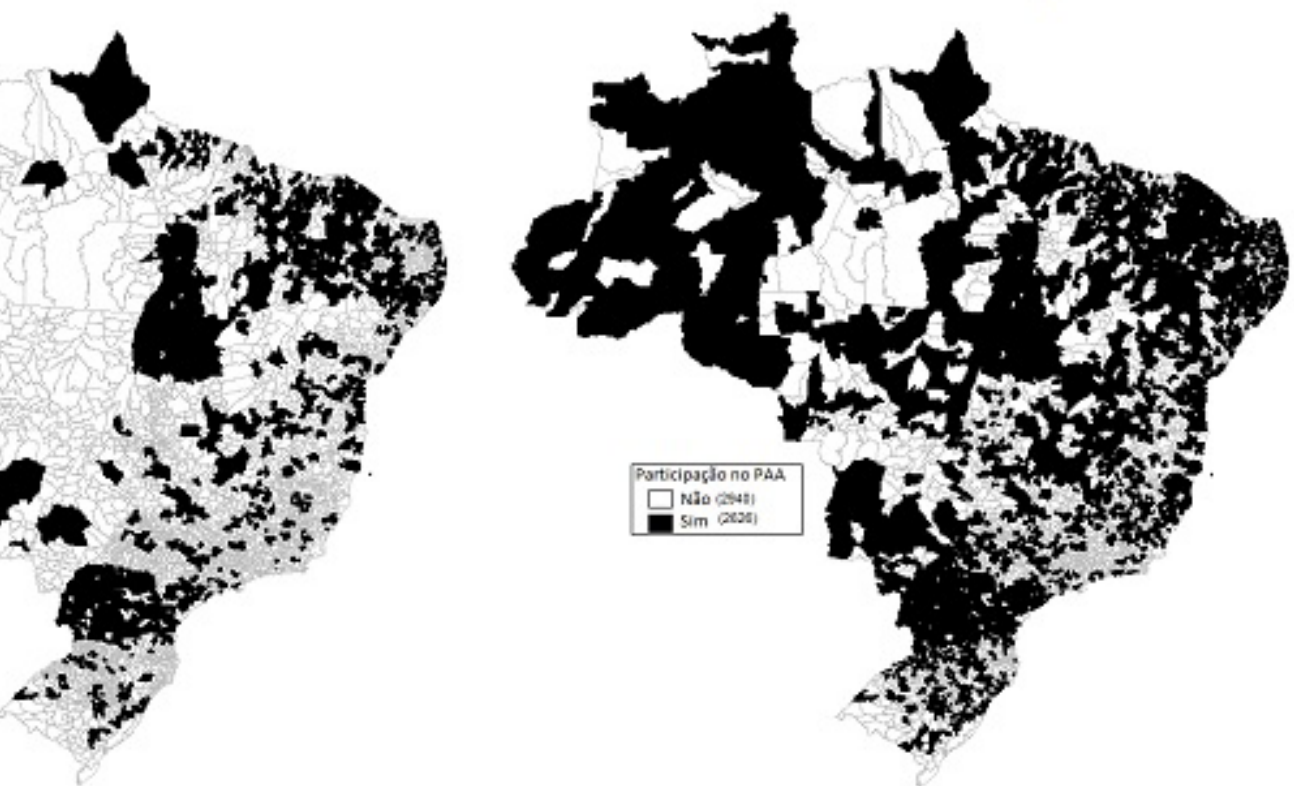

FIGURA 1 - Municípios que participaram do PAA entre 2012 e 2015 e taxa de crescimento dos recursos da modalidade operada pela Conab-Municípios do Brasil

Fonte: Conab e PAA DATA, com dados organizados pela pesquisa

Nota: (*) Em negrito estão os municípios que receberam algum valor do programa entre 2012 a 2015, não necessariamente recebendo durante todos os anos. (**) em negrito estão os municípios que receberam algum valor do programa entre 2012 a 2014 , não abrangendo 2015 pela indisponibilidade dos dados 
TABELA 2 - Recursos investidos no PAA e participação de cada região - 2012, 2013 e 2014 (IGP-DI, 2012=100)

\begin{tabular}{|c|c|c|c|c|c|c|c|}
\hline \multirow{2}{*}{ Ano } & \multirow{2}{*}{ PAA } & \multirow{2}{*}{ Valores (R\$) } & \multicolumn{5}{|c|}{ Participação (\%) } \\
\hline & & & Norte & Nordeste & Sudeste & Sul & Centro Oeste \\
\hline \multirow{3}{*}{$\stackrel{\sim}{\stackrel{\sim}{*}}$} & Municipal/Estadual & $114,946,149$ & 12 & 41 & 18 & 25 & 4 \\
\hline & Conab & $585,477,674$ & 6 & 26 & 23 & 38 & 7 \\
\hline & Total & $700,423,823$ & 7 & 29 & 22 & 36 & 7 \\
\hline \multirow{3}{*}{$\stackrel{n}{\stackrel{n}{d}}$} & Municipal/Estadual & $97,858,008$ & 23 & 36 & 9 & 30 & 2 \\
\hline & Conab & $196,799,608$ & 10 & 30 & 30 & 19 & 11 \\
\hline & Total & $294,657,616$ & 14 & 32 & 23 & 23 & 8 \\
\hline \multirow{3}{*}{$\underset{\sim}{\stackrel{\Xi}{\sim}}$} & Municipal/Estadual & $108,528,615$ & 17 & 46 & 13 & 21 & 3 \\
\hline & Conab & $285,528,134$ & 11 & 24 & 38 & 18 & 9 \\
\hline & Total & $394,056,749$ & 13 & 30 & 31 & 19 & 7 \\
\hline
\end{tabular}

Fonte: Conab e PAA DATA (2016), organizado pela pesquisa

Com as alterações efetuadas a partir de 2012, parte dessas funções foram descentralizadas. No novo modelo, o MDS faz a transferência de recursos diretamente para o agricultor, e os estados/prefeituras que participam do programa ficam responsáveis pelo registro no sistema informatizado (SIS-PAA) de todas as informações necessárias para que o MDS autorize esse pagamento. Ademais, os estados/municípios também ficam responsáveis pela emissão de toda a documentação fiscal referente à operacionalização do programa, acompanhando e fiscalizando a aquisição dos produtos, sua qualidade, além de armazenar e de entregar tais produtos. Ou seja, transferiu-se para as unidades executoras não somente a responsabilidade pela execução política, mas também pela administração, pelo planejamento e fiscalização do programa. Com isso, a expectativa é de expansão do programa, com maior controle público dos recursos empregados.

É importante destacar, porém, que essa descontinuidade dos montantes do PAA-CONAB pode resultar, concomitantemente, em efeitos negativos, perdendo esforços que vinham sendo empregados, principalmente, na organização dos agricultores em associações ${ }^{4}$. Com efeito, esse novo formato do PAA busca incluir beneficiários fornecedores isolados e não

${ }^{4} \mathrm{Na}$ principal modalidade do programa operada pelo pela Conab-compra com doação simultânea, que concentrava a maior proporção de agricultores fornecedores até 2012 - tinha como condicionalidade à vinculação dos agricultores a uma associação ou cooperativa, visando assegurar escala e variedade da produção, promovendo a auto-organização dos pequenos agricultores, funcionando como um mecanismo adicional de construção de sua autonomia produtiva. cooperativados em municípios pequenos e afastados das capitais, retirando o protagonismo de cooperativas e associações. Por um lado, incluem-se agricultores que estavam à margem do Programa, mas, ao mesmo tempo, Valdares e Souza (2015) argumentam que essa condicionalidade quanto à participação de organizações induz a estruturação produtiva das unidades familiares, bem como à ampliação da capacidade de oferta dos agricultores. Por isso, essa descontinuidade do programa nessas modalidades operadas pela Conab pode comprometer de forma específica a diversidade da produção do agricultor familiar, além de todo o trabalho realizado na articulação local entre produtores e unidades recebedoras beneficiadas pela entrega dos alimentos.

No caso dos pontos negativos, ainda não se consegue avaliar se o rumo tomado pelo programa acarretou nesse rompimento do processo de diversificação, de organização das propriedades; contudo, já é possível avaliar preliminarmente à meta de expansão do Programa. Com efeito, pela Tabela 2, tem-se os valores de cada modalidade desde 2012.

Observa-se que o PAA operado em nível municipal e estadual (Municipal/estadual) não supriu, em termos de valor, o que vinha sendo empregado anteriormente no programa (2012), mostrando uma perda de foco nesse processo de adaptação. Além do mais, ainda se percebe uma desigualdade dos valores distribuídos regionalmente, não tendo uma distribuição proporcional à concentração da agricultura familiar que se tem ao longo do país. É claro que se teve uma melhora, mas ainda está aquém do ideal frente à realidade brasileira. 
Embora em termos de valor o PAA tenha perdido fôlego, em termos de distribuição dos municípios que passaram a participar do programa se ganhou com a descentralização que se teve. Na Figura 1 (c), tem-se a distribuição dos municípios que participaram do PAAestadual/municipal em, pelo menos, um dos anos entre 2012 e 2014, englobando 1608 municípios. Se comparado com as informações da Figura 1(a), tem-se um número superior de municípios beneficiados (1608 contra 1552 das operações da Conab), com um agravante de que nas modalidades estaduais/ municipais se teve um valor bem menor que o administrado pela Conab. Ou seja, mesmo tendo um montante menor, as modalidades estaduais/ municipais conseguiram se fazer presentes num maior número de municípios, ao longo de todo o país, nesse período.

Somando as modalidades operadas pela Conab, pelos estados e pelos municípios, no decorrer de 2012$2015^{5}$, observa-se [Figura 1(d)] um grande número de municípios envolvidos, chegando a 2626. Em termos de evolução, considerando as três modalidades, tinha-se 1796 municípios participantes do PAA em 2012, e em 2014 ampliou-se, abrangendo 1818 municípios brasileiros (Tabela 3). Ademais, se analisar apenas os municípios envolvidos na modalidade estadual/municipal, vê-se um grande avanço, tendo um número de municípios em 2014 bem superior do que se tinha nas modalidades operadas pela Conab em 2012.

TABELA 3 - Municípios brasileiros que participaram do PAA - modalidades -2012 a 2015*

\begin{tabular}{ccccc}
\hline & 2012 & 2013 & 2014 & 2015 \\
\hline PAA Estadual + municipal & 792 & 678 & 1341 & - \\
PAA operações Conab & 1159 & 535 & 619 & 539 \\
PAA Total & 1796 & 1101 & 1818 & - \\
\hline
\end{tabular}

Fonte: PAA DATA, organizado pela pesquisa

Nota: (*) no caso do PAA estadual/municipal tem-se dados disponíveis apenas até o ano de 2014.

Portanto, com esses dados preliminares, pode-se inferir quanto à existência de uma expansão dos municípios participantes do PAA decorrente dessa descentralização, não existindo, porém, a mesma ampliação dos valores destinados ao programa como se tinha a priori.

${ }^{5}$ Lembrando que no caso das modalidades estaduais/municipais os valores somados foram de 2012 a 2014 por não estando disponíveis ainda no PAA DATA os valores referentes a 2015.
Esse resultado é reforçado por meio da estatística I de Moran (Tabela 4). Observa-se que quando se analisa a distribuição dos valores do PAA [linhas (a), (b), (c)] versus a distribuição referente à participação dos municípios no PAA [linhas (d), (e), (f)], este último apresenta uma distribuição menos aleatória do que o primeiro. $\mathrm{Ou}$ seja, ainda se tem pontos isolados do espaço brasileiro, recebendo os maiores montantes do Programa.

Ao mesmo tempo, no caso da descentralização, como o valor do I de Moran declinou quando comparado 2012 versus 2014 para a participação dos municípios no programa em todas as modalidades [linhas $(\mathrm{g}),(\mathrm{h})$, (k), (l)], é possível inferir que a descentralização vem ocorrendo, com uma distribuição espacial mais homogênea dos municípios no PPA. Resultado oposto foi encontrado para a distribuição dos valores do PAA, em 2012, versus 2014 [linhas (i), (j), (m), (n)], com intensificação da concentração dos espaços que detêm os maiores valores, bem como com a concentração dos espaços que detém os menores valores.

Por fim, as estatísticas I de Moran bivariadas entre as diferentes modalidades do PPA (Conab e estadual/ municipal) e a agricultura familiar deixam evidentes a importância da reformulação do programa para beneficiar, de forma mais direta, as maiores concentrações de agricultores familiares. Destarte, ao se fazer a relação entre a concentração espacial das modalidades municipais/ estaduais (tanto em termos de participação como também em termos de valor - variáveis endógenas) versus a localização dos estabelecimentos da agricultura familiar (variável exógena) há evidências de autocorrelação positiva, inferindo que municípios com altos (baixos) valores/participação no PAA estadual/municipal estão associados a municípios com altos (baixos) percentuais de estabelecimentos da agricultura familiar.

Ao mesmo tempo, ao se fazer a relação entre a concentração espacial das modalidades PAA-CONAB versus a localização dos estabelecimentos da agricultura familiar (variável exógena) somente há evidências de autocorrelação positiva para a participação dos municípios e não para os valores distribuídos, dado que a pseudosignificância da variável "valor do PAA-CONAB" leva à interpretação de ausência de autocorrelação (variável com probabilidade não significativa).

Portanto, a redefinição do Programa conseguiu condicionar os recursos do PAA para mais próximo das principais aglomerações da agricultura familiar, beneficiando espaços com maior adensamento dessa categoria. 
TABELA 4 - Estatística I de Moran - univariado e bivariado - municípios brasileiros

\begin{tabular}{|c|c|c|c|c|}
\hline & Rainha & Torre & 4 vizinhos & 5 vizinhos \\
\hline Valor PAA Conab** (a) & $0,07 *$ & $0,07 *$ & $0,06^{*}$ & $0,06^{*}$ \\
\hline Valor PAA estadual/municipal $* * *(b)$ & $0,14^{*}$ & $0,13^{*}$ & $0,13^{*}$ & $0,14 *$ \\
\hline Valor PAA total $* * * *(\mathrm{c})$ & $0,08^{*}$ & $0,08^{*}$ & $0,07 *$ & $0,07 *$ \\
\hline Participação no PAA Conab (d) & $0,19^{*}$ & $0,19^{*}$ & $0,18^{*}$ & $0,16^{*}$ \\
\hline Participação no PAA estadual/municipal (e) & $0,46^{*}$ & $0,45^{*}$ & $0,45^{*}$ & $0,44 *$ \\
\hline Participação no PAA total (f) & $0,31 *$ & $0,30 *$ & $0,31 *$ & $0,29 *$ \\
\hline Participação no PAA estadual/municipal 2012 (g) & $0,58^{*}$ & $0,58 *$ & $0,57 *$ & $0,58 *$ \\
\hline Participação no PAA estadual/municipal 2014 (h) & $0,43^{*}$ & $0,43^{*}$ & $0,42 *$ & $0,43 *$ \\
\hline Valor PAA estadual/municipal 2012 (i) & $0,13^{*}$ & $0,13^{*}$ & $0,13^{*}$ & $0,12 *$ \\
\hline Valor PAA estadual/municipal 2014 (j) & $0,20 *$ & $0,20 *$ & $0,19^{*}$ & $0,20 *$ \\
\hline Participação no PAA Conab 2012 (k) & $0,16^{*}$ & $0,16^{*}$ & $0,16^{*}$ & $0,15 *$ \\
\hline Participação no PAA Conab 2014 (1) & $0,12 *$ & $0,12 *$ & $0,12 *$ & $0,12 *$ \\
\hline Valor PAA Conab 2012 (m) & 0,03 & 0,03 & 0,03 & 0,02 \\
\hline Valor PAA Conab 2014 (n) & $0,05^{*}$ & $0,05^{*}$ & $0,06^{*}$ & $0,05^{*}$ \\
\hline Bivariado: (a) versus partic. da agricultura familiar no total estab. & 0.004 & 0,004 & 0,006 & 0,005 \\
\hline Bivariado: (b) versus partic. da agricultura familiar no total estab. & $0,06^{*}$ & $0,06^{*}$ & $0,06^{*}$ & $0,06^{*}$ \\
\hline Bivariado: (c) versus partic. da agricultura familiar no total estab. & 0,009 & 0,009 & 0,01 & 0,02 \\
\hline Bivariado: (d) versus partic. da agricultura familiar no total estab. & $0,07 *$ & $0,07 *$ & $0,07 \&$ & $0,07 *$ \\
\hline Bivariado: (e) versus partic. da agricultura familiar no total estab. & $0,11^{*}$ & $0,11 *$ & $0,10^{*}$ & $0,11 *$ \\
\hline Bivariado: (f) versus partic. da agricultura familiar no total estab. & $0,12 *$ & $0,12 *$ & $0,12 *$ & $0,12 *$ \\
\hline
\end{tabular}

Nota: Pseudossignificância empírica baseada em 999 permutações aleatórias. (*) Probabilidade inferior a 5\%. $(* *)$ soma dos valores 2012 a 2015. (***) soma dos valores 2012 a 2014. (****) soma do PAA operado pelo Conab (2012 a 2015) e do PAA estadual e municipal (2012 a 2014)

\section{CONSIDERAÇÕES FINAIS}

Programas voltados para a fomentação da agricultura familiar são importantes, em razão da composição que se tem na agricultura brasileira, em que pequenas áreas comportam uma grande quantidade de agricultores, ao passo que a maior parte das terras pertencem a poucos.

Nesse sentido, o PAA torna-se um programa estratégico para o desenvolvimento rural do país ao demandar produção dos agricultores familiares, especialmente produtos que não exijam grandes áreas para sua produção, garantindo mercado, gerando renda suficiente para manter o produtor e sua família com determinada qualidade de vida.

Da forma como estava sendo executado até o ano de 2012, apresentava uma distribuição ao longo do país, atendendo a todas as regiões, no entanto, ficava aquém do seu resultado especialmente pelos limites de implementação e de execução do programa, o qual era significativamente centralizado.
Com as mudanças que ocorreram pós 2012 a expectativa era de descentralização do PAA, com ampliação de seu acesso para um número maior de municípios brasileiros. Os resultados demonstraram que isso efetivamente aconteceu, embora se tenham diminuído os montantes destinados para tal fim. Ademais, comprovou-se que com a descentralização privilegiou os pontos do país que, de forma mais acentuada, concentram a agricultura familiar.

O que se espera é que o programa avance, não só em termos de municípios participantes, mas principalmente em termos de valor empregado, prosseguindo com a distribuição que vem se dando, para que mais municípios se beneficiem dos resultados diretos e indiretos do PAA. Ademais, é necessário pensar na reestruturação dos agricultores, ao longo do acesso do programa, para que eles criem uma autonomia, diversificando e planejando a sua propriedade. Para isso, ações coadjuvantes são necessárias, seja, por instituições de assistência técnica, institutos de pesquisas, universidades, dentre outros, visando a 
colaborar na formação e organização dos agricultores, especialmente os que se enquadram na extrema pobreza.

\section{REFERÊNCIAS}

ALMEIDA, E. Econometria espacial aplicada. Campinas: Editora Alínea, 2012.

BECKER, C.; ANJOS, F. S.; BEZERRA, A. J. Os impactos do Programa de Aquisição de Alimentos da agricultura familiar na segurança alimentar e no desenvolvimento rural. 48 ${ }^{\circ}$ Congresso SOBER - Sociedade Brasileira de Economia, Administração e Sociologia Rural. Campo Grande, 2009.

BEZERRA, I. e SCHNEIDER, S. Produção e consumo de alimentos: o papel das políticas públicas na relação entre plantar e comer. Revista Faz Ciência, v.14, p. 1-20, 2012.

GRISA, K e PORTO, S. I. Dez anos de PAA: As contribuições e os desafios para o desenvolvimento rural. In: GRISA, K. e SCHNEIDER, S. (org). Políticas públicas de desenvolvimento rural no Brasil. Porto Alegre: Editora da UFRGS, 2015.

GRISA, K. e SCHNEIDER, S. (org). Políticas públicas de desenvolvimento rural no Brasil. Porto Alegre: Editora da UFRGS, 2015.

HESPANHOL, R. A. M. Programa de Aquisição de Alimentos (PAA) na Região de Dracena. $4^{\circ}$ SOBER. Sociedade Brasileira de Economia, Administração e Sociologia Rural, Porto Alegre. 2009.

R.A.M. Programa de Aquisição de Alimentos: limites e potencialidades de políticas de segurança alimentar para a agricultura familiar. Soc. \& Nat., Uberlândia, v.25, n.3, p.469-483, set/dez de 2013.

IBGE. Censos agropecuários. Disponível em:www.ibge. gov.br. Acesso em agost. 2016.
JUNIOR, A. A. B; ALMEIDA, E. Os principais fatores internos e as exportações microrregionais brasileiras. Revista Economia Contemporânea, Rio de Janeiro, v. 13, n. 2, p. 201-227, mai/ago 2009.

LEAL, S. C. T. O Programa de Aquisição de Alimentos (PAA) no Pontal do Paranapanema/SP. Revista NERA. Presidente Prudente Ano 18, $n^{\circ} .26$ - Edição especial pp. 147-164, 2015.

MATOS, T. S. e NOIA, A. C. Análise do desempenho do Programa de Aquisição de Alimentos no município de Itabuna-BA. IV Semana do Economista e IV Encontro de Egressos. Universidade Estadual de Santa Cruz UESC. Ilhéus - Bahia, 2014.

PAA DATA. Disponível em:http://aplicacoes.mds.gov. br/sagi/paa/visi_paa_geral/pg_principal.php?url=abertura Acesso agost. 2016.

PEREIRA, M. E. B. de G. e LOURENZANI, A. E. B. $\mathrm{S}$. Desafios e perspectivas do programa de aquisição de alimentos no município de Tupã - SP. Ciência e Natura, Santa Maria, v. 36 n.2 mai-ago. 2014, p. 230-240.

VALADARES, A.A.; SOUZA, M.G.P. A trajetória recente do Programa de Aquisição de Alimentos da Agricultura Familiar (PAA): uma análise das mudanças normativas e institucionais que deram nova inflexão ao programa. Nota técnica IPEA, n. 21, dez 2015.

PEIXOTO, A. M. M.; OLIVEIRA, A. O. A abordagem territorial nas políticas públicas de desenvolvimento rural: uma análise do PAA para a produção camponesa no município de Ipameri-GO. - Presidente Prudente: Revista NERA - Ano 18, nº 26 - Edição especial, p. 70-91, 2015.

VINHA, J. F. S. C. SCHIAVENATTO, M. Soberania Alimentar e territórios camponeses: uma análise do Programa de Aquisição Alimentos (PAA). Revista NERA. Presidente Prudente. Ano 18, no 26 - Edição Especial.Pg 183 a 203. 2015. 